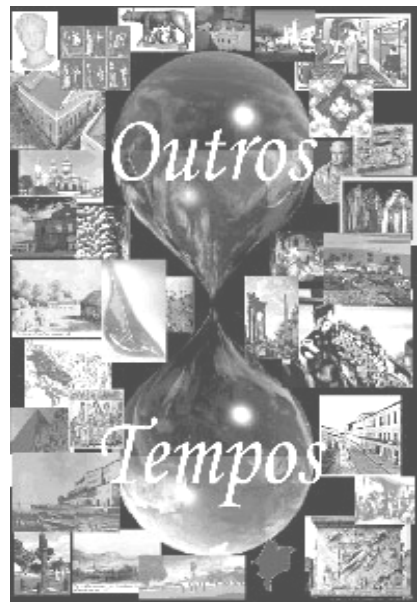

\title{
HISTÓRIA E MEMÓRIA NO CHILE CONTEMPORÂNEO.
}

Janaína Capistrano

Mestre em Sociologia UNESP, Doutoranda em História e Cultura

Política UNESP e Professora do curso de Ciências Sociais Universidade Federal do Tocantins.

Resumo: Este artigo buscou realizar uma discussão acerca do problema das relações entre memória e história, a partir de algumas considerações sobre acontecimentos recentes da história chilena. Nesse trajeto, desvelou-se que o processo de resgate do passado e as estratégias seladas para tal resgate configuram-se claramente como programas políticos, o que remete o historiador a uma reflexão sobre seu protagonismo enquanto sujeito produtor de conhecimento.

Palavras chave: Memória, história, Chile.

Abstract: This article aims to discuss the relations between memory and history, discussing about the current political facts in Chilean history. In this way, it can be understood that the process of to rescue the past and the strategies to this reach it is configuring, clearly, a political program. This Idea leads the historian to discuss about its main character while a knowledge maker

Keywords: Memory, History and Chile.

\section{INTRODUÇÃO.}

Em dezembro de 2006, no Chile, a morte o ex-ditador Augusto Pinochet levou milhares de pessoas a dois pontos opostos da principal avenida da capital Santiago. Alguns grupos se concentraram-se diante do palácio do governo "La Moneda" e se manifestaram numa espécie de comemoração ao óbito desse importante personagem da história recente chilena. Por outro lado, um grande número de pessoas seguiu, com pesar, o cortejo fúnebre até o edifício da "Escola Militar", situada num outro extremo da avenida, onde seria velado o corpo e oferecidas honras militares.

Naquela ocasião, autoridades, políticos, intelectuais, associações, partidos e militares, dentre outras organizações e lideranças, pronunciaram-se sobre o ocorrido, ora frisando, positivamente, o papel de Pinochet, na condução da revolução neoliberal no país, 
ora denotando sua responsabilidade na violação de direitos humanos e no mau uso e destinação do dinheiro público, o que simboliza o fato de que, "para uma parte da sociedade chilena, ele [Pinochet] representou a dor, o trauma, o medo e a desesperança; para outra, o esplendor de um novo e próspero Chile, livre da ameaça do Comunismo, tornando a indiferença em relação a um personagem como esse uma coisa ociosa" (AGGIO, 2006, s/p.).

De qualquer forma, a despeito das diferenças nas concepções sobre a experiência pretérita da ditadura e das diferentes reações que daí emergiram, com a morte de Pinochet, o passado invadiu o presente dos chilenos convocando-os a se manifestarem a respeito desse tempo e tudo o que ele carregava. E isso representa um fenômeno instigante no desencadeamento de uma reflexão sobre memória e história pois, afinal, estas instâncias do pensamento humano referem-se ao passado e representam duas modalidades de relação com esse tempo.

\section{ENTRE A MEMÓRIA E O ESQUECIMENTO: contrapontos de uma luta política no Chile atual.}

Muito se escreveu sobre memória, no Chile, principalmente após a transição à democracia, em 1990, quando a perspectiva metodológica sobre esse fenômeno serviu para questionar a história produzida na segunda metade do século XX, no país. Essa história, reconhecida como oficial, foi considerada parte integrante de uma "política para o esquecimento". História que, além da escrita da história, teria mobilizado, também, outras estratégias, com o fim de ocultar os rastros dos crimes cometidos sob a ditadura, e certos termos selados, no pacto sócio-político para a transição. Dentre tais estratégias, seria possível citar a publicação de documentos oficiais, o programa de anistia, e a relação oficial com o patrimônio físico.

Em relação ao pacto sócio-político para a transição, um dos seus pontos mais polêmicos foi o papel e o alcance dos trabalhos da Comissão Nacional de Verdade e Reconciliação, cujo relatório final apontou claramente para a existência de repetidas violações dos direitos humanos por parte de agentes do Estado entre 1973 e 1990. Para os críticos, o protagonismo da Comissão tinha direta relação com o esclarecimento da 
"verdade" sobre os acontecimentos passados e, nesse sentido, poderia contribuir para que uma "memória proibida" se convertesse em "memória aberta" (CÁCERES, 1999, p 1-4) 1.

$\mathrm{Na}$ esteira dos debates sobre verdade, memória e história, um conjunto de historiadores chilenos publicou um documento intitulado "Manifesto de Historiadores", onde se reivindicava a tarefa de "indagar, escrever e promover iniciativas de recuperação da memória popular" e se apontava para a necessidade imperiosa de se redigir e fazer circular uma história dos grupos sociais até então marginalizados nas narrativas (GREZ e SALAZAR, 1999, p.47). Boa parte das proposições do Manifesto esteve baseada em informações oriundas do trabalho realizado pelos historiadores assinantes do texto, na "Oficina Nova História”, a qual fora fundada em 1979. E sobre essas informações e o trabalho na Oficina os autores escreveram:

La experiencia de los talleres de recuperación de la memoria, nos demostró que la memoria social podía ser una manera muy importante de resistir culturalmente a la verdad oficial. Esa verdad arrogante y acrítica, y sin derecho a réplica de los vencidos, que se proclamaba diariamente por los medios de comunicación, controlados o dirigidos por adherentes o funcionarios del régimen militar. La historia, admitimos entonces, no era sólo el texto propuesto por el historiador, sino también memoria y oralidad, memoria e identidad, que de modo particular preservan los grupos populares en nuestro país. En efecto, a través de nuestras propuestas metodológicas las personas que participaban de los talleres, podían reconocerse con historia [...] (GREZ e SALAZAR, 1999, p.48).

Nesse trecho, o problema do estabelecimento de uma verdade genuína sobre o passado aparece condicionado ao resgate de uma memória social. Ademais, esse resgate surge como uma ação possível de ser dinamizada pelos historiadores, como se evidencia na proposta das "oficinas de recuperação da memória", orientadas por estes sujeitos. Um espaço de atividades voltadas, no limite, para a função política da memória, pois capazes de concretizar uma "réplica dos vencidos".

Assim, é possível verificar, na proposta da Nova História chilena, uma abordagem historiográfica congruente com a abordagem da historiografia, "em sua versão moderna", a qual se encontra esteada na idéia de exercício de controle sobre a memória (SELIGMANSILVA, 2003, p.61). Além disso, e também de maneira congruente à historiografia moderna, verifica-se uma profunda crença no papel político da memória que se relaciona a

\footnotetext{
${ }^{1}$ O texto de Cáceres (1999) intitulado "As sombras da memória no Chile dos anos noventa: da indução ao esquecimento à primavera das lembranças", pode dar uma boa mostra da discussão gerada no país sobre a política para o esquecimento e as formas de superá-la.
} 
uma intenção de estabelecimento da veracidade sobre os acontecimentos. Demonstrando como uma "vontade de verdade" está ligada à adoção de determinada perspectiva e de determinado arsenal metodológico (GAGNEBIN, 1998).

\section{ADENTRANDO A REFLEXÃO SOBRE OS USOS E ABUSOS DA MEMÓRIA.}

As diferentes abordagens da historiografia e as questões relativas à aproximação ou à oposição existente na relação entre história e memória demandaram uma ampliação da discussão sobre o estatuto teórico da memória que, em síntese, teve quatro implicações (SEIXAS, 2001, p $37-43$ ).

Uma dessas implicações foi a valorização das pesquisas sobre a memória, em geral, e sobre a memória de grupos marginais, correspondendo a uma "valorização das memórias silenciadas, mas não esquecidas" (SEIXAS, 2001, p. 43). Um segundo ponto refere-se ao aparecimento de uma consciência da vulnerabilidade teórica da memória, essencialmente em relação aos seus mecanismos de produção e reprodução (SEIXAS, 2001, p. 44).

Em terceiro lugar, e relacionando-se com o segundo ponto, encontra-se a atenção voltada para o problema do tempo e do espaço percorrido pela memória, ou seja, o problema da atualização da memória e da sua espacialização. E, por fim, o questionamento dos limites da função política da memória (SEIXAS, 2001, p. 44 - 45).

Sobre os mecanismos de produção e reprodução, os momentos da história onde a memória irrompe com mais força, surpreendendo, muitas vezes, os observadores do fenômeno, e o diálogo transdisciplinar que valoriza, sobretudo, elementos da filosofia e da literatura universal ${ }^{2}$, revelam a impossibilidade de o historiador exercer controle total sobre a memória.

Seria impossível para esse sujeito narrar o passado por completo e reproduzi-lo no presente, mesmo pautando-se no testemunho ou na memória. Isso porque, no momento de sua emergência, a memória traria fragmentos do passado separados e selecionados por mecanismos pouco conhecidos e que fogem do domínio do investigador (SELIGMANSILVA, 2003).

\footnotetext{
${ }^{2}$ Boa parte das considerações de Seixas (2001 e 2002) baseia-se num diálogo realizado com Proust e Bérgson.
} 
Nesse sentido, ao historiador, estaria negada a possibilidade de reapresentar o passado, em suas narrativas, tal como se deram os acontecimentos, quer dizer, em sua integralidade, pois, nem as lembranças e nem o esquecimento, caem sob seu domínio. O prefixo "re" da palavra reapresentar remete à idéia de totalidade, de reprodução fiel dos acontecimentos pretéritos, o que não é possível de ser realizado, trata-se, portanto, de uma nova apresentação do passado (SELIGMAN-SILVA, 2003).

Logo, se a memória é o meio de acesso ao passado, e este não pode ser reapresentado, que dimensão da memória vem sendo apresentada pela historiografia? E esta questão se volta também, e muito, para os trabalhos que privilegiaram o resgate ou a recuperação da memória dos excluídos e dos marginalizados nas narrativas da história oficial, com vistas ao estabelecimento da verdade. Como, por exemplo, no citado caso chileno.

Essencialmente, em virtude dos procedimentos metodológicos adotados nessa disciplina, a dimensão da memória, comumente apresentada, teria sido aquela dimensão deliberada e planejadamente evocada, cujo resgate é estimulado ou realizado pelo próprio historiador, a chamada "memória voluntária" (SEIXAS, 2001, 2002). Como ocorria nas oficinas de recuperação da memória, promovidas pela "Oficina Nova História" no Chile.

No entanto, há uma dimensão desse fenômeno que emerge espontaneamente e, por isso, encontra-se sempre acompanhada de sentimentos. O que quer dizer que, diferentemente da dimensão voluntária, a qual estaria marcada pelas atitudes conscientes e pela racionalidade, haveria uma dimensão involuntária carregada de afetividade e espontaneidade, a chamada "memória involuntária” (SEIXAS, 2001).

A esse respeito, Seixas (2001) observa que:

Não há memória involuntária que não venha carregada de afetividade e, ainda que a integralidade do passado esteja irremediavelmente perdida, aquilo que retorna vem inteiro, íntegro, porque com suas tonalidades emocionais e charme afetivo (SEIXAS, 2001, p 47).

Entretanto, a afirmação de que a memória involuntária traz um passado íntegro, ou mais íntegro do que aquele trazido pela memória voluntária, pois carrega consigo as emoções, conduz à idéia de que os elementos apresentados por essa dimensão, dantes desprezada encontram-se mais próximos de uma verdade sobre os acontecimentos do passado. Isso vem legitimando o trabalho do historiador que sobre as manifestações da memória involuntária se debruça porque, antes, esta corrobora a si mesma. Assim, os 
fragmentos de memória que poderiam ser apreendidos pelo pesquisador seriam tanto mais fiéis aos acontecimentos do passado quanto mais relacionados à memória involuntária. Como se através de uma espécie de "ato falho" freudiano fosse possível descobrir segredos do passado, porque tais segredos irromperiam tal como um "ato falho" e informariam aquilo que racionalmente não se informaria.

Diante disso, teria o historiador que esperar pacientemente por essas irrupções da memória afetiva, para prosseguir com suas interpretações e narrativas? Ora, se esse sujeito lança mão de algum instrumento para estimular a rememoração estará ativando a dimensão voluntária da memória e se afastando da verdade sobre o passado?

Essas questões conduzem ao tratamento da problemática da atualização e da espacialização da memória, a qual, por sua complexidade, não poderá, de nenhuma maneira, ser esgotada aqui, mas merece, ao menos, ser considerada.

Dialogando com Proust e Bérgson, Seixas (2001) observa que o presente é o tempo de onde se desencadeia a memória e esta, por sua vez, é desencadeada pela percepção. Dessa maneira, a percepção promove a associação entre presente e memória e viabiliza, assim, as noções de presente, passado e futuro, as quais orientarão os pensamentos e as ações dos indivíduos e grupos.

O passado é, nesse sentido, atualizado no presente, mas já não é apenas passado, porque, como a percepção se deu no presente, o que a memória atualiza é algo comum ao passado e ao presente. Atualiza-se algo que, sem ser real é atual, revela-se a essência atemporal dos acontecimentos e das coisas. Por conseguinte, tem-se que, a atualização pela memória mostra o caráter construtivista deste fenômeno, uma vez que, a cada instante do presente, e a cada nova percepção que conduz ao passado, surge a possibilidade de algo único (SEIXAS, 2001).

De onde se conclui, por um lado, que não há verdade sobre o tempo pretérito, pois este é sempre lido sob a luz do presente, e o presente sempre pode ser outro (SELIGMANSILVA, 2003). E, por outro lado, que é a natureza da percepção que determina o acesso às dimensões da memória.

Mas o historiador pode criar um determinado ambiente onde coloque determinadas possibilidades de percepções que desencadeiem um processo de rememoração do grupo social que está trabalhando, por exemplo? Se a resposta é positiva, isso quer dizer que, 
dessa maneira, ele poderá acessar apenas a dimensão voluntária? Para acessar a dimensão involuntária necessita esperar que os indivíduos e/ou grupos sociais que observa acessem a memória a partir da percepção de um evento aleatório ou ocasional? Como foi a morte de Pinochet, por exemplo. E a questão inicial permanece, quanto o observador, terá de esperar e em que direção deverá olhar?

A respeito da espacialização da memória, a historiografia possui um papel fundamental ao assumir a tarefa de reintroduzir na pauta do dia temas e acontecimentos traumáticos. Pois isso significa dar um lugar para tais temas e acontecimentos, um lugar que não é o esquecimento completo. O registro da história é importante, já que não seria possível esquecer, ou melhor dizendo, superar aquilo que não se conhece. Daí, que essa tarefa assimila-se a uma tarefa ética, que viabiliza a perlaboração e, conseqüentemente, a superação de traumas históricos que cindem sociedades inteiras. (SELIGMAN-SILVA, 2003).

Um último ponto interessante, conexo à espacialização da memória, está relacionado à idéia de rastros, os quais se constituiriam em indícios da memória e, ao que tudo indica, poderiam assumir formas objetivas ou subjetivas. Uma tarefa importante para a historiografia consiste em evitar que os rastros dos acontecimentos, os quais também podem representar lugares de memória, se apaguem. Deixar que esses rastros desapareçam, poderá significar a repetição de erros e horrores históricos. "Por isso é uma tarefa altamente política lutar contra o esquecimento e a denegação, é também lutar contra a repetição do horror. [...] Por isso a preocupação com a verdade sobre o passado se completa na exigência de um presente que também possa ser verdadeiro", entendendo que esta verdade não é universal, é antes uma preocupação com verdades pautadas nos rastros (GAGNEBIN, 1998, p.220).

Retoma-se assim, a questão da função política da memória, mas agora não mais como pauta nas estratégias para o estabelecimento de uma verdade única e totalizante, mas sim enquanto argumento para a perlaboração e para a preservação dos rastros. 


\section{CONSIDERAÇÕES FINAIS}

Em relação ao Chile, e pensando do ponto de vista do problema da produção e reprodução da memória, as manifestações relativas à morte de Pinochet constituíram-se em expressão de memórias carregadas de afetividade - alegria, tristeza, ódio, paixão - e desvelaram um daqueles momentos citados por Seixas, onde a memória irrompe "pelos poros e cicatrizes sociais" sinalizando realidades afetivas antes submersas no cotidiano dos indivíduos e dos grupos sociais (SEIXAS, 2001, p.37).

Num primeiro momento, a produção de textos analíticos sobre esse evento foi intensa, mas pouco se explicou sobre como e porque, por um lado, o ex-ditador permanecera "com tanto apoio na sociedade chilena depois de derrotado no plebiscito de 1988, detido em Londres por crimes contra os direitos humanos e desmoralizado em razão de processos de evasão fiscal no exterior". E por outro lado, como e porque sua morte fora comemorada "como se ela fosse fazer passar as dores que provocou" e a despeito de a justiça nunca tê-lo condenado (AGGIO, 2006). Essa lacuna explicativa deixou em aberto para os historiadores da memória o problema dos ressentimentos no Chile.

Como a própria palavra indica, o ressentimento é um sentimento que nasce a partir de situações pretéritas e permanece nos subterrâneos da memória até voltar à tona e ser novamente sentido. $\mathrm{O}$ ressentimento pode representar um sistema sócio-afetivo, formado por três elementos básicos. Em primeiro, lugar estão "os sentimentos difusos de ódio, de inveja, de hostilidade"; em segundo, a sensação de impotência para expressar esses sentimentos difusos e, por fim, a experiência intermitente de uma "impotente hostilidade" (ANSART, 2001, p. 14, 18, 19).

Observando o caso chileno, possivelmente se diagnosticará a presença dessas três facetas sistêmicas. Os sentimentos difusos encontram-se latentes, entre prós-pinochetistas e contra-pinochetistas, como indicam os ressentes acontecimentos no país. ${ }^{3}$ A sensação de impotência para expressar tais sentimentos também não pode ser descartada da realidade chilena se se observa, por exemplo, o longo período transcorrido pelos processos judiciais, abertos contra os possíveis violadores dos direitos humanos, sem que houvessem condenações significativas e as consecutivas derrotas das organizações de direita na arena

\footnotetext{
${ }^{3}$ Após as manifestações em torno do evento da morte do ex-ditador, ocorreram violentos confrontos entre esses grupos opostos na capital Santiago.
} 
política. Isso tudo não deixa dúvidas sobre a existência da experiência de uma impotente hostilidade vivida entre os chilenos.

O tema dos ressentimentos e os problemas apresentados pela irrupção da memória afetiva propõem ao historiador o "desafio de restituir e explicar o devir dos sentimentos individuais e coletivos" pois, muitas vezes, "os ódios coletivos são decisivos no desenlace dos acontecimentos históricos". Seria importante, portanto, "formular a hipótese do papel do inconsciente na política" (ANSART, 2001, p. 28,29).

Em termos sócio-políticos, enquanto tipo ideal o sistema democrático permitiria superar, ou ao menos gerir pacificamente, os ódios e as oposições existentes entre indivíduos e grupos que convivessem sob sua égide. Ademais, permitiria romper com o sentimento de impotência, por meio do reconhecimento das pessoas e dos seus direitos. Por conseguinte, se daria uma gestão democrática dos ressentimentos, pautada na ação corrente e coerente das instituições e seus agentes, embora isso na prática seja pouco simples (ANSART, 2001).

No Chile, por exemplo, a ditadura militar reprimiu violentamente e proibiu qualquer expressão de seus opositores durante dezessete anos. E demarcando o desfecho desse período, exerceu grande protagonismo no processo de transição à democracia, consolidando, a longo prazo, o que se chamou de "enclaves autoritários" e "justiça de transição". Os enclaves constituem-se em heranças institucionais da ditadura, impostas através da promulgação da Constituição de 1980, a qual vigora até hoje, no país. Os mais significativos desses dispositivos institucionais, que asseguram certo conservadorismo nas transformações sócio-políticas, são os Senadores designados e vitalícios, o Conselho de Defesa do Estado, a estabilidade dos Chefes das Forças Armadas e o sistema eleitoral binominal. Já a "justiça de transição" tem a ver com os mecanismos de saída de um passado de violência política, relacionados a uma forma de justiça que não é a justiça penal. Nesse sentido, tais mecanismos, atendem, antes ao objetivo de estabilização política, do que ao objetivo de "restauração da dignidade das vitimas e o estabelecimento de um relato histórico razoável" (LEFRANC, 2003, s/p).

Com vistas à estabilização política, privilegiou-se, no país, a anistia e um discurso onde o perdão generalizado aparece como única forma de se evitar a repetição do horror. Contudo, quase duas décadas depois de iniciado o processo de transição, a organização chilena "Agrupación de Familiares de Detenidos Desaparecidos" continua reivindicando 
uma justiça que condene os culpados e os envie ao presídio. Por fim, a experiência de reconciliação acabou constituindo-se numa solução negativa, pois não gerou uma democracia onde o dissenso sobre o passado favorecesse um diálogo nacional e promovesse, assim, uma catarse coletiva e, por conseguinte, a consolidação de relações políticas de acordo com as normas liberais, ou seja, onde as relações de oposição sejam de adversários e não de inimigos (LEFRANC, 2003, s/p).

Tal panorama dificulta, certamente, a perlaboração sugerida por Seligman-Silva (2003), a gestão democrática dos ressentimentos, como sugere Ansart (2001) e a catarse coletiva, por meio do diálogo sobre as verdades do passado, recomendada por Lefranc (2003). E, ao mesmo tempo, confere urgência ao tratamento da memória pelos historiadores.

A incisiva censura impediu que, durante o desenrolar dos acontecimentos, os vencidos produzissem seu patrimônio cultural relativo à sua vivência no período. $\mathrm{O}$ tipo de repressão, desencadeada foi pródiga em ocultar as provas e os corpos dos crimes, cancelando possibilidades de condenação e de luto. Conseqüentemente, e associada à política de anistia, essa repressão invalidou o registro documental nos autos da justiça dos nomes das vítimas e dos seus algozes. Tudo isso interfere na questão da atualização e da espacialização da memória, porque elimina os rastros e os lugares de memória, logo, impõe desafios ético-políticos ao historiador.

Como apontou Burke (2006), a morte impediu que Pinochet fosse condenado, mas ao mesmo tempo abriu uma oportunidade para que se falasse, abertamente, de um passado traumático, se rompesse tabus e se trouxesse para a superfície memórias antes reprimidas.

Nesse sentido, a percepção da ausência definitiva do ex-ditador, através da memória carregada de afetividade, ligou o passado ao presente dos chilenos, que se manifestaram a respeito daquilo que recordavam e daquilo que desejavam para seu futuro. A Presidente Michelle Bachelet abordou o problema da seguinte maneira:

Tengo memoria, creo en la verdad, aspiro a la justicia y tengo la profunda convicción y la voluntad para superar la adversidad, los momentos amargos e injustos y entender que, como en los ciclos personales, también en los ciclos de la historia de una nación se abren nuevos derroteros donde lo que aprendimos del pasado nos debe ayudar para enfrentar mejor el futuro. [...] Chile no puede olvidar, sólo así tendremos una mirada constructiva de nuestro porvenir, garantizando el respeto a los derechos fundamentales de todas y todos los chilenos (IBLNEWS, 2006, s/p). 
No trecho, é interessante notar a presença de referências a elementos que circundam toda problemática da memória, tais como vontade de verdade, esquecimento, justiça e relação determinante entre as noções de presente, passado e futuro. A projeção de futuro aparece claramente associada a um tratamento adequado do passado e da memória. Poderá o historiador contribuir com essa tarefa?

\section{REFERÊNCIAS}

AGGIO, A. Chile: um símbolo antidemocrático. Gramsci e o Brasil / La Insignia. Brasil, dezembro de 2006. Disponível em: http://www.lainsignia.org/2006/diciembre/ibe_048.htm

ANSART, P. História e memória dos ressentimentos. In: BRESCIANI, S \& NAXARA, M. Memória e (re)sentimento: indagações sobre uma questão sensível. Campinas: UNICAMP, 2001. p.15-36.

BURKE, P. Julgando Pinochet. Folha de S. Paulo, Mais, 3/2/2007. Disponível em: http://www2.metodista.br/unesco/rede_alcar/Rede_Alcar_75/capitulos_midia_3.htm

CÁCERES Q., G. El claroscuro de la memoria colectiva en el Chile de los noventa: de la inducción al olvido a la primavera de los recuerdos. Disponível em: http://www.uv.es/ jalcazar/gonza4.htm

GAGNEBIN, J. "Verdade e memória do passado". Projeto História - trabalhos da memória. São Paulo: PUC, nº 17, novembro/98. p.213-221.

GREZ S. e SALAZAR, G. Manifesto de historiadores. LOM: Santiago do Chile, 1999.

IBLNEWS. Más de 60.000 personas desfilan ante el féretro de Pinochet. Disponível em: http://iblnews.com/story_se.php?id=20644

LEFRANC, S. "Aquello que no se comemora. ¿Democracias sin un pasado compartido?” Revista de Ciência Política. Santiago, v.23, nº 2, 2003. p. 231-240 (versión online- scielo)

SEIXAS, J. A. "Os campos (in)elásticos da memória: reflexões sobre a memória histórica”. In: SEIXAS, J. A.; BRESCIANI, M. S. \& BREPOHL, M. (org.) Razão e paixão na política. Brasília: UNB, 2002. p. 59-77

"Percursos de memórias em terra de história: problemáticas atuais". In:

BRESCIANI, M. S. \& NAXARA, M. Memória e (re)sentimento: indagações sobre uma questão sensível. Campinas: UNICAMP, 2001. p.37 - 58

SELIGMANN-SILVA, M. "Reflexões sobre a memória, a história e o esquecimento". In: SELIGMANN-SILVA, M. História, memória e literatura - O testemunho na Era das Catástrofes. Campinas, UNICAMP, 2003. p.59-90. 